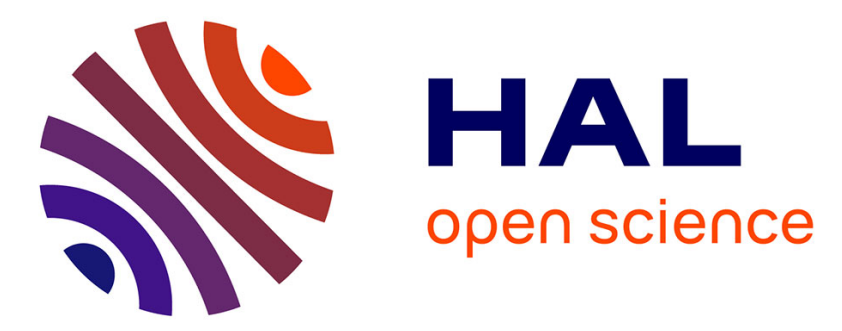

\title{
Volume of spinopelvic muscles: comparison between adult spinal deformity patients and asymptomatic subjects
}

\author{
Emmanuelle Ferrero, Wafa Skalli, Marc Khalifé, Robert Carlier, Antoine \\ Feydy, Adrien Felter, Pierre Guigui, Virginie Lafage
}

\section{To cite this version:}

Emmanuelle Ferrero, Wafa Skalli, Marc Khalifé, Robert Carlier, Antoine Feydy, et al.. Volume of spinopelvic muscles: comparison between adult spinal deformity patients and asymptomatic subjects. Spine Deformity, In press, 10.1007/s43390-021-00357-9 . hal-03271331

\section{HAL Id: hal-03271331 \\ https://hal.science/hal-03271331}

Submitted on 25 Jun 2021

HAL is a multi-disciplinary open access archive for the deposit and dissemination of scientific research documents, whether they are published or not. The documents may come from teaching and research institutions in France or abroad, or from public or private research centers.
L'archive ouverte pluridisciplinaire $\mathbf{H A L}$, est destinée au dépôt et à la diffusion de documents scientifiques de niveau recherche, publiés ou non, émanant des établissements d'enseignement et de recherche français ou étrangers, des laboratoires publics ou privés. 


\title{
Volume of spinopelvic muscles: comparison between adult spinal deformity patients and asymptomatic subjects
}

\author{
Emmanuelle Ferrero ${ }^{1,2} \cdot$ Wafa Skalli $^{2} \cdot$ Marc Khalifé $^{1} \cdot$ Robert Carlier $^{4} \cdot$ Antoine Feydy $^{5} \cdot$ Adrien Felter $^{4}$. \\ Pierre Guigui ${ }^{1} \cdot$ Virginie Lafage ${ }^{3}$
}

\begin{abstract}
Purpose Spinal muscles are a major component of posture in spinal pathologies and changes to the spine with aging. Specifically, spinopelvic muscles may compensate for underlying anomalies such as pelvic retroversion, knee flexion, and cervical or thoracic spinal balance abnormalities. To increase understanding between muscular characteristics and compensatory mechanisms, this study aimed to compare the volume of spinopelvic muscles in adults with a spinal deformity (ASD) to a control group of well-aligned adult subjects.

Methods Twenty-eight lumbar ASD patients [Cobb angle $>20^{\circ},>40$ years old (yo)] were prospectively included and compared to 35 normal subjects divided into 2 different groups: one group of young (Y) subjects $(n=23,<20$ yo) and one group of old (O) subjects $(n=12,>40$ yo). All subjects had a fat/water separation MRI (from C7 to the knees). Volumetric 3D reconstructions of 30 spinopelvic muscles were performed and muscles volumes were compared.

Results Mean age was $60 \pm 16$ yo, without significant differences between the ASD and O groups (57 \pm 11 yo). Age and BMI were smaller in the young group. Mean Cobb angle of the ASD group was $45 \pm 11^{\circ}$. Comparing the ASD and $\mathrm{O}$ groups, total muscular volume was similar; however, erector spinae $\left(0.24 \pm 0.06\right.$ vs $\left.0.68 \pm 0.08 \mathrm{dm}^{3}, p=0.001\right)$, iliopsoas $(0.49 \pm 0.09$ vs $\left.0.60 \pm 0.09 \mathrm{dm}^{3}, p=0.001\right)$ and obliquus $\left(0.42 \pm 0.08\right.$ vs $\left.0.50 \pm 0.08 \mathrm{dm}^{3}, p=0.02\right)$ were significantly smaller in the ASD group. Comparing the $\mathrm{Y}$ and the ASD groups, total muscular volume was higher in the Y group than the ASD group (+3.3 $\left.\mathrm{dm}^{3}, p=0.003\right)$ and erector spinae $(0.24 \pm 0.06$ vs $0.74 \pm 0.08, p=0.0001)$, gluteus medius $(0.51 \pm 0.07$ vs $0.62 \pm 0.13$, $p=0.01)$ and vastus lateralis $(1.33 \pm 0.21$ vs $2.08 \pm 0.29, p=0.001)$ were significantly bigger in the $\mathrm{Y}$ group.

Conclusion This is the first study to compare volume of spinopelvic muscles between ASD patients and a control group without spinal deformity. Our results demonstrate that muscular degeneration has a double origin: aging and deformity. Erector spinae, iliopsoas, and obliquus are the muscles most affected by degeneration.
\end{abstract}

Keywords Adult spinal deformity $\cdot$ Muscle degeneration $\cdot 3 \mathrm{D}$ analysis $\cdot$ Scoliosis $\cdot$ Fat infiltration

Emmanuelle Ferrero

emmanuelle.ferrero@aphp.fr

1 Department of Orthopaedic Surgery, Georges Pompidou European Hospital, APHP, Paris V University, 20 rue Leblanc, 75015 Paris, France

2 Laboratoire de Biomécanique Georges Charpak, Ecole Nationale Supérieure des Arts et Métiers, 75013 Paris, France

3 SpineLab, Department of Orthopaedic Surgery, Hospital for Special Surgery, New York, , NY, USA

4 Department of Radiology, Hospital de Garches, APHP, Garches, France

5 Department of Radiology, Hospital Cochin, APHP, Paris V University, Paris, France

\section{Introduction}

The prevalence of adult scoliosis is increasing with an aging population and surgical treatment is more and more frequent, despite the high rate of complications (up to $40 \%$ in some series, mostly mechanical) $[1,2]$. The pathophysiology of scoliosis in adults is multifactorial, involving several degenerative processes: bone, discs, muscles and central nervous system [3-5]. It remains poorly understood and adult spinal deformity (ASD) is complex.

Many studies have evaluated the specificities of radiographic alignment in ASD, particularly with the analysis of sagittal parameters and alignment which are well correlated with physical function and life quality [6, 7]. 
Spinal muscles are of the upmost importance for global postural control and their lack of function is certainly involved in the development of spinal pathologies. However, muscle structure also deteriorates with age. To maintain an erect posture and alignment while standing, spinopelvic and lower limb muscles may compensate for an abnormal segment's position. For example, elderly patients with degenerative spinal deformities, frequently decrease their lumbar lordosis with subsequent pelvic retroversion, hip hyperextension and knee flexion at the lower segments and thoracic kyphosis and cervical lordosis at the upper segments [8-10]. Thus, a better understanding of the muscles' role and their degeneration in the development of ASD could allow for better treatments. However, few authors have investigated the volume and fat infiltration of pelvic and spinal muscles.

Some studies on muscle involvement and properties in subjects without spinal deformities have shown an increase in fat infiltration up to $15 \%$ with aging [11]. Similarly, some authors have observed decreases in muscle volume and increased fat infiltration of the spinal erector muscles in patients with a loss of lumbar lordosis $[12,13]$. Others have also shown an association between fat infiltration increases and low back pain [14]. However, most of these studies were based on surface analyses which did not allow accurate muscle volume assessment.

The use of new MRI reconstruction methods allows better quantification and identification of muscles properties, which increases our understanding on their impact on spinal deformity evolution [15-17]. However, only one study has analyzed relationships between radiographic and muscular parameters [12]. Moreover, to the best of our knowledge, no work has compared muscles properties between ASD patients and asymptomatic subject without spinal deformity.

The aim of this study was, therefore, to compare volumes of spinopelvic muscles between ASD patients to a control group of well-aligned subjects to identify muscles characteristics and the potential compensatory mechanisms developed in spinal deformities.

\section{Methods}

\section{Patients}

This study was conducted prospectively between 2016 and 2018, after ethics committee approval. Patients over 40 years old (P group), with degenerative or old idiopathic lumbar scoliosis with a Cobb angle greater than $20^{\circ}$ were selected for inclusion. Only primary cases and with a complete imaging assessment (3D full-spine $\mathrm{X}$-ray and muscular MRI) were included. Patients with a history of spinal surgery or another cause of scoliosis (neurological, congenital, traumatic or neoplastic) were excluded. ASD patients were compared to 2 control groups without spinal deformity and without back pain from previous studies: one group of young subjects (Y group, $n=23,<20$ yo) and one group of old subjects ( $\mathrm{O}$ group, $n=12,>40$ yo).

\section{MRI analysis}

MRI was performed in all patients from the T12 vertebra to the femoral condyles. The axial slices were consecutive, parallel and contiguous with a constant thickness of $5 \mathrm{~mm}$. The fat/water separation MRI protocol used was the same as the one described in a previous study (Dixon method) [12, 18]. The MRI machine was set with the following parameters: $\mathrm{TR} / \mathrm{TE}=427 / 11.3 \mathrm{~ms}$, acquisition matrix $=416 \times 416$ pixels, phase oversampling $=100 \%$, in plane resolution $=0.82 \mathrm{~mm}^{2}$, 8 stages, 40 slices by stage, slice thickness $=5 \mathrm{~mm}$, slice gap $=0 \mathrm{~mm}$, parallel imaging acceleration factor(iPat) $=2$, bandwidth $=391 \mathrm{~Hz} /$ pixel, echo spacing $=11.3 \mathrm{~ms}$, acquisition time per stage $=7 \mathrm{~min}$, total acquisition time $=50 \mathrm{~min}$ $[19,20]$. A first set of images where the intensity of each voxel was correlated with the amount of water (Water image) and a second set of images where the intensity of each voxel was correlated with the amount of fat (Fat image) were automatically generated. These two sequences had exactly the same slice positions and orientations.

Using the DPSO (deformation of parametric specific object) method with dedicated software (Muscl'X, ENSAM, Paris, France), volumetric 3D reconstructions and fat infiltration (FI) of right and left muscles were performed (with information from all MRI slices) [21] (Fig. 1). The following muscles were studied: latissimus dorsi, erector spinae (spinalis, longissimus and iliocostalis), rectus abdomini, iliopsoas, quadratus lumborum, obliquus (external, internal and transverse), gluteus (maximus, medius, minimus), long and short heads of biceps femoris, semi-tendinosus, semimembranosus, quadriceps (vastus lateralis, vast medialis, rectus femoris), gracilis, Sartorius, tensor of fascia lata and the adductors. To be comparable to the two asymptomatic populations, the relative volume of each muscle was also calculated (muscle volume/ total muscular volume of the patient).

\section{Statistical analysis}

Statistical analyses were performed using Stata 15.0 (Statacorp, College Station, Texas). A Shapiro-Wilk test was performed to assess data distribution showing continuous distribution. A descriptive analysis of demographic and muscle data was performed. Relative muscle volumes were compared between groups with a Student $T$ test. A $p<0.05$ was considered significant. 


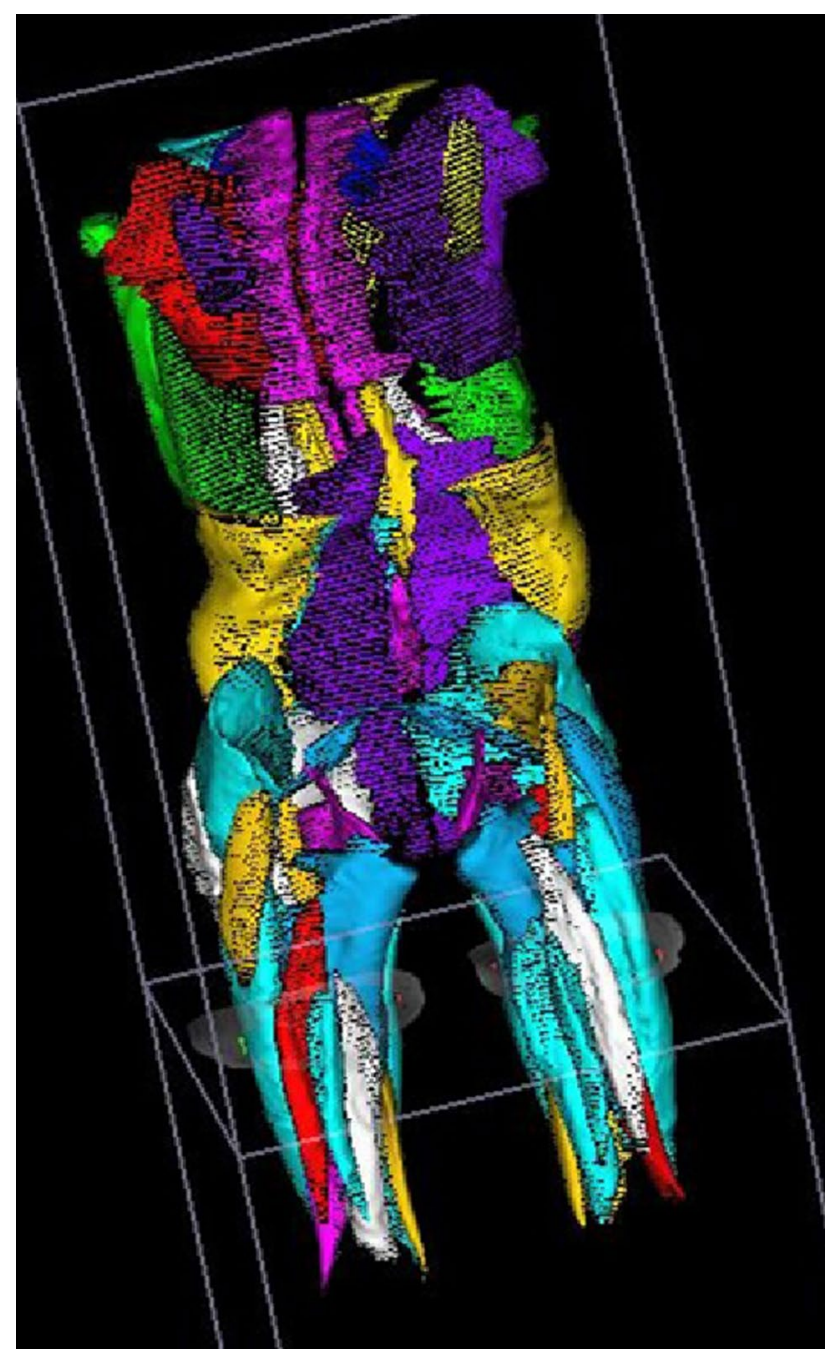

Fig. 1 Volumetric 3D muscular reconstruction of an ASD patient

\section{Results}

\section{Demographic data}

Mean age of the 28 ASD patients included was $60 \pm 16$ years, with $71 \%(n=20)$ women and a mean body mass index of $26 \pm 4 \mathrm{~kg} / \mathrm{m}^{2}$. Age and body mass index were not significantly different between these patients and the old group $\left(57 \pm 11\right.$ years, $\left.25 \pm 6 \mathrm{~kg} / \mathrm{m}^{2}\right)$. In contrast, the young group body mass index was lower $\left(21 \pm 2 \mathrm{~kg} / \mathrm{m}^{2}, p=0.03\right)$, and logically these subjects were significantly younger $(19 \pm 1$ year, $p=0.02)$. Mean Cobb angle in the patient group was $45 \pm 11^{\circ}$ (Table 1).
Table 1 Sagittal radiographic parameters of 28 adults with lumbar scoliosis

\begin{tabular}{llrrr}
\hline & Mean & SD & Min & Max \\
\hline Pelvic incidence $\left(^{\circ}\right)$ & 55 & 11 & 31 & 80 \\
Pelvic tilt $\left(^{\circ}\right)$ & 21 & 8 & 10 & 38 \\
L1S1 $\left(^{\circ}\right)$ & 43 & 21 & 10 & 89 \\
PI-LL $\left(^{\circ}\right)$ & 11 & 16 & -17 & 37 \\
T1T12 $\left({ }^{\circ}\right)$ & 38 & 15 & 2 & 75 \\
C3C7 $\left(^{\circ}\right)$ & 23 & 16 & -9 & 48 \\
SVA $(\mathrm{mm})$ & 51 & 49 & -71 & 146 \\
\hline
\end{tabular}

L1S1 means L1S1 lumbar lordosis, PI-LL pelvic incidence minus lumbar lordosis, T1T12 T1T12 thoracic kyphosis, C3C7 cervical lordosis, $S V A$ sagittal vertical axis

Table 2 ASD patients' muscular volumes $(n=28)\left(\mathrm{dm}^{3}\right)$

\begin{tabular}{lllll}
\hline Muscles & Mean $\times 10^{-1}$ & SD & Min $\times 10^{-1}$ & $\operatorname{Max} \times 10^{-1}$ \\
\hline Latissimus dorsi & 3.6 & 0.1 & 0.9 & 9.1 \\
Erector spinae & 2.4 & 0.1 & 0.1 & 6.8 \\
Spinalis & 1.4 & 0.0 & 0.8 & 2.4 \\
Longissimus & 2.0 & 0.0 & 0.8 & 4.1 \\
Iliocostalis & 1.1 & 0.0 & 0.3 & 1.9 \\
Iliopsoas & 4.9 & 0.1 & 0.1 & 9.4 \\
Quadratus lumborum & 0.4 & 0.0 & 0.1 & 1.2 \\
Rectus abdomini & 2.7 & 0.0 & 1.3 & 4.2 \\
Obliquus & 4.2 & 0.1 & 1.8 & 7.2 \\
\hline
\end{tabular}

Table 3 Muscular volumes of old controls (O group, $n=12)\left(\mathrm{dm}^{3}\right)$

\begin{tabular}{lllll}
\hline Muscles & Mean $\times 10^{-1}$ & SD & Min $\times 10^{-1}$ & $\operatorname{Max} \times 10^{-1}$ \\
\hline Latissimus dorsi & 0.9 & 0.0 & 0.2 & 2.4 \\
Erector spinae & 6.8 & 0.1 & 4.8 & 9.4 \\
Spinalis & 1.4 & 0.0 & 0.8 & 2.0 \\
Longissimus & 1.6 & 0.0 & 1.0 & 2.6 \\
Iliocostalis & 2.1 & 0.0 & 1.2 & 3.6 \\
Iliopsoas & 6.0 & 0.1 & 3.8 & 0.6 \\
Quadratus lumborum & 0.4 & 0.0 & 0.3 & 1.1 \\
Rectus abdomini & 2.6 & 0.1 & 1.4 & 4.1 \\
Obliquus & 5.0 & 0.1 & 2.8 & 7.4 \\
\hline
\end{tabular}

\section{Muscle data}

\section{Old controls ( 0 ) vs ASD patients (P)}

Total muscle volumes of the patients and the old group were not significantly different $\left(2.71 \pm 0.8 \mathrm{dm}^{3}\right.$ vs $2.69 \pm 0.7 \mathrm{dm}^{3}$, $p=0.94)$. Mean muscles volumes analyzed in the patients and old groups are reported in Tables 2 and 3.

Analysis of the relative volumes revealed that the relative volume of erector spinae was significantly greater in 
the old group than in patients (O: $25 \pm 2 \%$ vs P: $16 \pm 4 \%$, $p=0.0001)$. Results were similar for iliocostalis (O: $7 \pm 1 \%$ vs P: $4 \pm 1 \%, p=0.000)$. However, no significant difference was observed for the longissimus and the spinalis. Iliopsoas and quadratus lumborum were larger in the old group than in the patient group (respectively, O: $22 \pm 4 \%$ vs P: $18 \pm 4 \%$, $p=0.001$ and $\mathrm{O}: 2 \pm 0.4 \%$ vs $\mathrm{P}: 1.4 \pm 0.5 \%, p=0.003$ ). The relative volume of the obliquus was also greater in the old group than in the patients group (O: $18 \pm 2 \%$ vs P: $15 \pm 3 \%$, $p=0.02$ ), whereas no difference existed for rectus abdomini (Fig. 2). Concave and convex sides of ASD patients were compared without any significant differences found in muscular volume.

\section{Young controls $(\mathrm{Y})$ vs ASD patients $(\mathrm{P})$}

Patients total muscular volume was significantly smaller than in the young subjects (P: $7.80 \pm 2.5 \mathrm{dm}^{3}$ vs Y: $11.11 \pm 3.5$ $\mathrm{dm}^{3}, p=0.0003$ ). Muscles' volumes studied in the patients and young subjects are summarized in Tables 4 and 5. Analysis of relative muscles' volumes revealed that erector spinae were significantly greater in the young group than in the patients (Y: $7 \pm 1 \%$ vs P: $5 \pm 1 \%, p=0.000$ ). Findings were similar for iliopsoas (Y: $7 \pm 1 \%$ vs P: $5 \pm 1 \%, p=0.0003$ ), quadratus lumborum (Y: $0.9 \pm 0.1 \%$ vs $\mathrm{P}: 0,5 \pm 0.1 \%$, $p=0.000$ ), rectus femoris (Y: $4.2 \pm 0.4 \%$ vs P: $3.4 \pm 0.6 \%$, $p=0.000)$ and vastus lateralis (Y: $19 \pm 1 \%$ vs $\mathrm{P}: 15 \pm 2 \%$, $p=0.0003$ ). However, relative muscle volume was greater in the patients group for gluteus medius (Y: $5.6 \pm 0.6 \%$ vs P: $6.4 \pm 1 \%, p=0.007)$ and long head of biceps femoris (Y: $3.0 \pm 0.4 \%$ vs P: $3.4 \pm 1 \%, p=0.01$ ) (Fig. 3). No significant differences were reported between the young and patients' groups for gluteus maximus, gluteus minimus,
Table 4 ASD patients' muscular volumes $(n=28)\left(\mathrm{dm}^{3}\right)$

\begin{tabular}{lcclc}
\hline Muscles & Mean $\times 10^{-1}$ & SD & Min $\times 10^{-1}$ & Max $\times 10^{-1}$ \\
\hline Erector spinae & 2.4 & 0.1 & 0.1 & 6.8 \\
Iliopsoas & 4.9 & 0.1 & 0.1 & 9.4 \\
Quadratus lumborum & 0.4 & 0.0 & 0.2 & 1.3 \\
Gluteus magnus & 1.8 & 0.1 & 6.0 & 17.2 \\
Gluteus medius & 5.1 & 0.1 & 2.4 & 7.2 \\
Gluteus minimus & 1.3 & 0.0 & 0.6 & 2.4 \\
Rectus femoris & 2.8 & 0.0 & 1.6 & 4.8 \\
Vastus lateralis & 13.3 & 0.2 & 5.2 & 24.1 \\
Vastus medius & 5.4 & 0.1 & 0.8 & 11.2 \\
Tensor fascia lata & 1.1 & 0.0 & 0.4 & 2.1 \\
Gracilis & 1.2 & 0.0 & 0.5 & 2.8 \\
Sartorius & 2.0 & 0.0 & 0.8 & 4.1 \\
Adductors & 4.0 & 0.2 & 5.6 & 23.2 \\
Short biceps femoris & 1.2 & 0.0 & 0.1 & 2.0 \\
Long biceps femoris & 2.6 & 0.0 & 0.6 & 4.1 \\
Semi-membranosus & 2.8 & 0.1 & 0.8 & 5.0 \\
Semi-tendinosus & 2.4 & 0.1 & 0.7 & 2.6 \\
\hline
\end{tabular}

vastus medialis, tensors of the fascia lata, gracilis, sartorius, adductors, short femoral biceps, semi-membranosus and semi-tendinosus.

\section{Discussion}

In this study, muscle volumes of ASD patients were compared to two populations (young and old) of asymptomatic subjects without deformities. It appears that certain muscles of ASD patients have a loss of volume, which is both
Fig. 2 Muscular volumes of ASD patients and old controls (*significant difference for relative volume between groups)

\section{Muscular volume $\left(\mathrm{dm}^{3}\right)$}

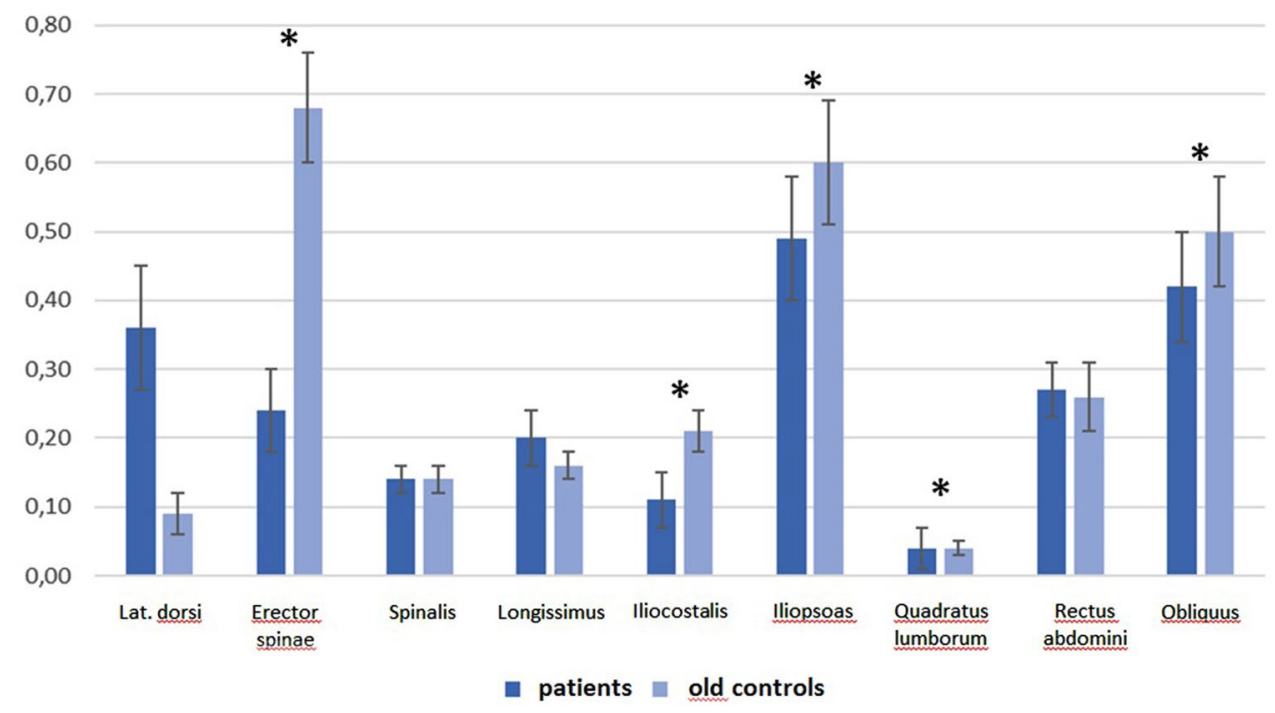


Table 5 Muscular volumes of young controls (Y group, $n=23)\left(\mathrm{dm}^{3}\right)$

\begin{tabular}{lrrrr}
\hline Muscles & Mean $\times 10^{-1}$ & SD & Min $\times 10^{-1}$ & Max $\times 10^{-1}$ \\
\hline Erector spinae & 7.4 & 0.1 & 5.0 & 10.8 \\
Iliopsoas & 4.9 & 0.1 & 2.1 & 16.1 \\
Quadratus lumborum & 8.4 & 0.0 & 2.2 & 1.8 \\
Gluteus magnus & 15.8 & 0.4 & 9.4 & 48.0 \\
Gluteus medius & 6.2 & 0.1 & 3.6 & 16.4 \\
Gluteus minimus & 1.8 & 0.0 & 1.2 & 4.4 \\
Rectus femoris & 4.6 & 0.1 & 3.2 & 6.8 \\
Vastus lateralis & 20.8 & 0.3 & 13.9 & 38.4 \\
Vastus medius & 8.0 & 0.1 & 5.4 & 14.0 \\
Tensor fascia lata & 1.2 & 0.0 & 0.5 & 2.6 \\
Gracilis & 1.8 & 0.0 & 0.5 & 2.6 \\
Sartorius & 2.8 & 0.1 & 14.1 & 6.4 \\
Adductors & 18.1 & 0.3 & 11.6 & 38.1 \\
Short biceps femoris & 1.8 & 0.0 & 0.9 & 3.6 \\
Longs biceps femoris & 3.2 & 0.1 & 1.8 & 6.2 \\
Semi-membranosus & 4.1 & 0.1 & 2.6 & 11.2 \\
Semi-tendinosus & 3.2 & 0.1 & 1.8 & 5.4 \\
\hline
\end{tabular}

linked to sarcopenia and to the deformation itself. Thus, the analysis of the relative muscle volume on the total muscle volume was used to more accurately assess muscle degeneration from the disease and not from normal aging changes.
This was demonstrated by our findings that there was no difference in total muscle volume between our patients and the old group while on the other hand, the total muscle volume of young subjects was significantly larger, by more than 2 $\mathrm{dm}^{3}(2 \mathrm{~L})$.

Compared to the young group, the flexors and extensors of the spine were reduced in muscle volume in the ASD group. Similarly, among the flexors of the spine, both iliopsoas and quadratus lumborum were significantly smaller in muscle volume in the ASD group. The quadriceps (hip flexor) was also altered in ASD group with a significant reduction in the muscle volume of the vastus lateralis and rectus femoris compared to young subjects. Thus, degeneration of trunk stabilizer muscles was observed in the ASD compared to the young controls. In contrast, relative muscle volumes of the long head of biceps femoris (hip extensor) and gluteus medius (hip stabilizer) were larger in the ASD group. This might be explained by the need to compensate for the malalignment in ASD patients: the gluteus medius for coronal malalignment compensation and the long head of biceps femoris for sagittal malalignment to increase pelvic retroversion.

Comparing ASD patients to elderly subjects without deformity showed spinal flexors and extensors were reduced in relative volume in the deformity group. Among the erectors, it was in particular the iliocostalis which was the most

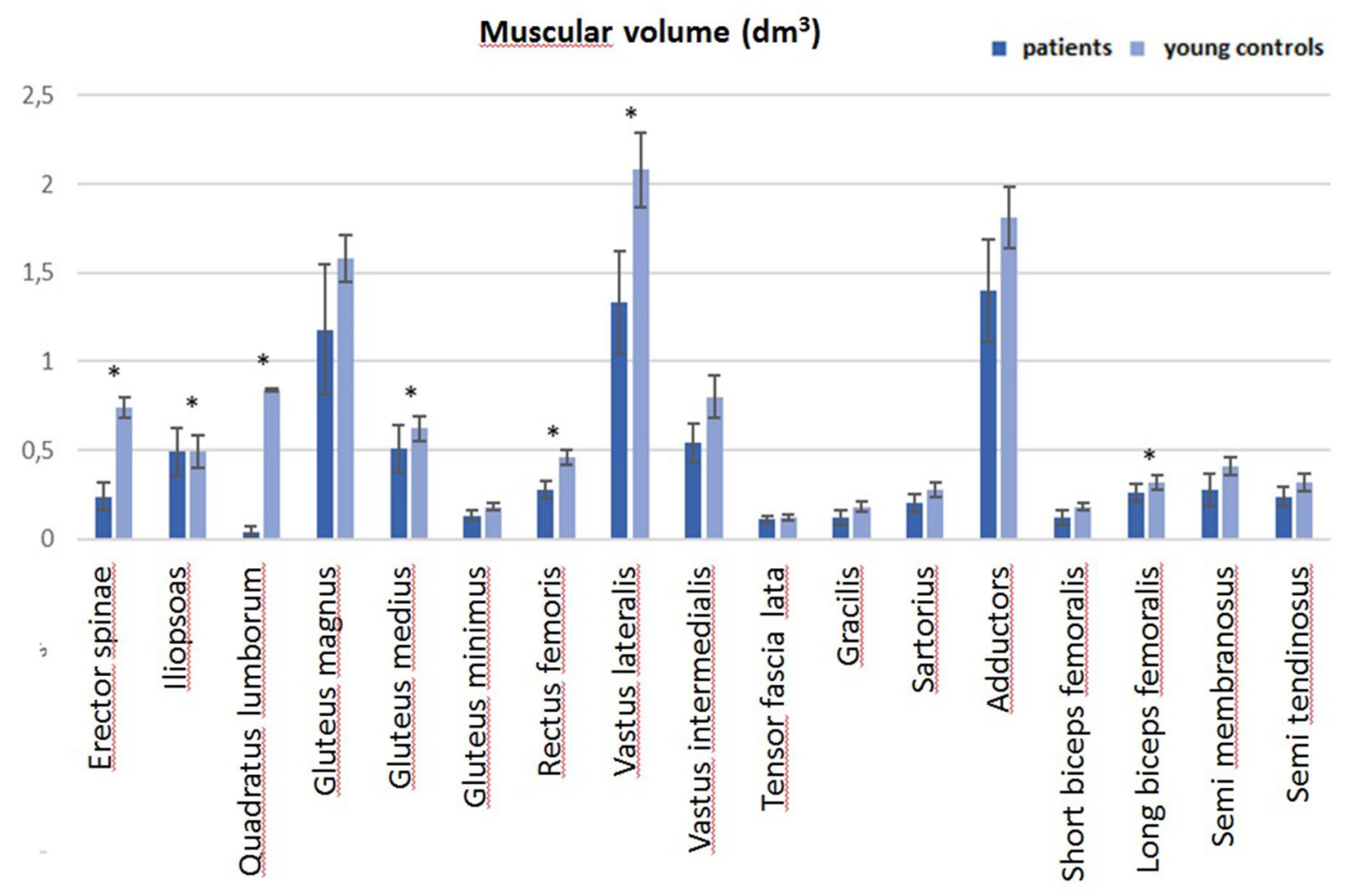

Fig. 3 Muscular volumes of ASD patients and young controls (*significant difference for relative volume between groups) 
affected by degeneration. Among spine flexors, both iliopsoas and quadratus lumborum were relatively significantly less voluminous in ASD patient group. There was no difference in the volume of rectus abdomini between groups, however, obliquus was also relatively less voluminous in ASD patients. These findings demonstrate that axial trunk muscles were affected by the deformity associated with spinal erectors and flexors degeneration. However, the primary cause is still not yet understood: whether degenerated muscles cause the deformity or the deformity triggers axial trunk muscles degeneration will need to be investigated in further studies. Nevertheless, these results emphasized that both spinal erector and flexors are affected by age and deformity.

In our study, aging and spinal deformity demonstrate an association with alteration of the trunk stabilizer muscles (Fig. 4). In another study on ASD patients, we have previously shown that the most affected muscle group by fat infiltration was the group of spinal erectors (34\%), closely followed by spinal flexors (32\%) [12]. The least affected muscles were hip flexors and extensors (19\% and 18\%). This earlier study also showed that sagittal malalignment (pelvic retroversion of more than $20^{\circ}$, of SVA of more than $40 \mathrm{~mm}$, of PI-LL of more than $10^{\circ}$ ) was significantly associated with greater fat infiltration of spinal flexors and extensors. Pelvic retroversion was also associated with increased fat infiltration of the gluteus medius. In addition, in cases of lumbar lordosis loss, all spinopelvic muscle groups had increased fat infiltration. All these degenerative phenomena can be associated with difficulty in maintaining an erect posture. Moreover, relationships have also been observed between axial intervertebral rotation and muscle degeneration. Moal et al. were the first to use this MRI method in spinal pathology when they described the muscle characteristics of 19 adult patients with spinal deformity but without X-rays [18]. Amabile et al. more recently, in a cohort of young subjects without deformity reported the values of muscle volumes from T12 to the femoral condyles, thus constituting the first reference values in asymptomatic subjects [15].

Degeneration of spinal flexors and extensors was observed in this study of ASD patients. This loss of volume is linked to both aging and deformity, given the differences observed with the young and old controls. However, the loss of muscle volume at the quadriceps level compared to young subjects can be linked to both a decrease in activity in these patients and also posture imbalance. Postural imbalance leads to greater stress on the hip extensors at the expense of the hip flexors. Finally, the relative increase in the volume of the gluteus medius in these

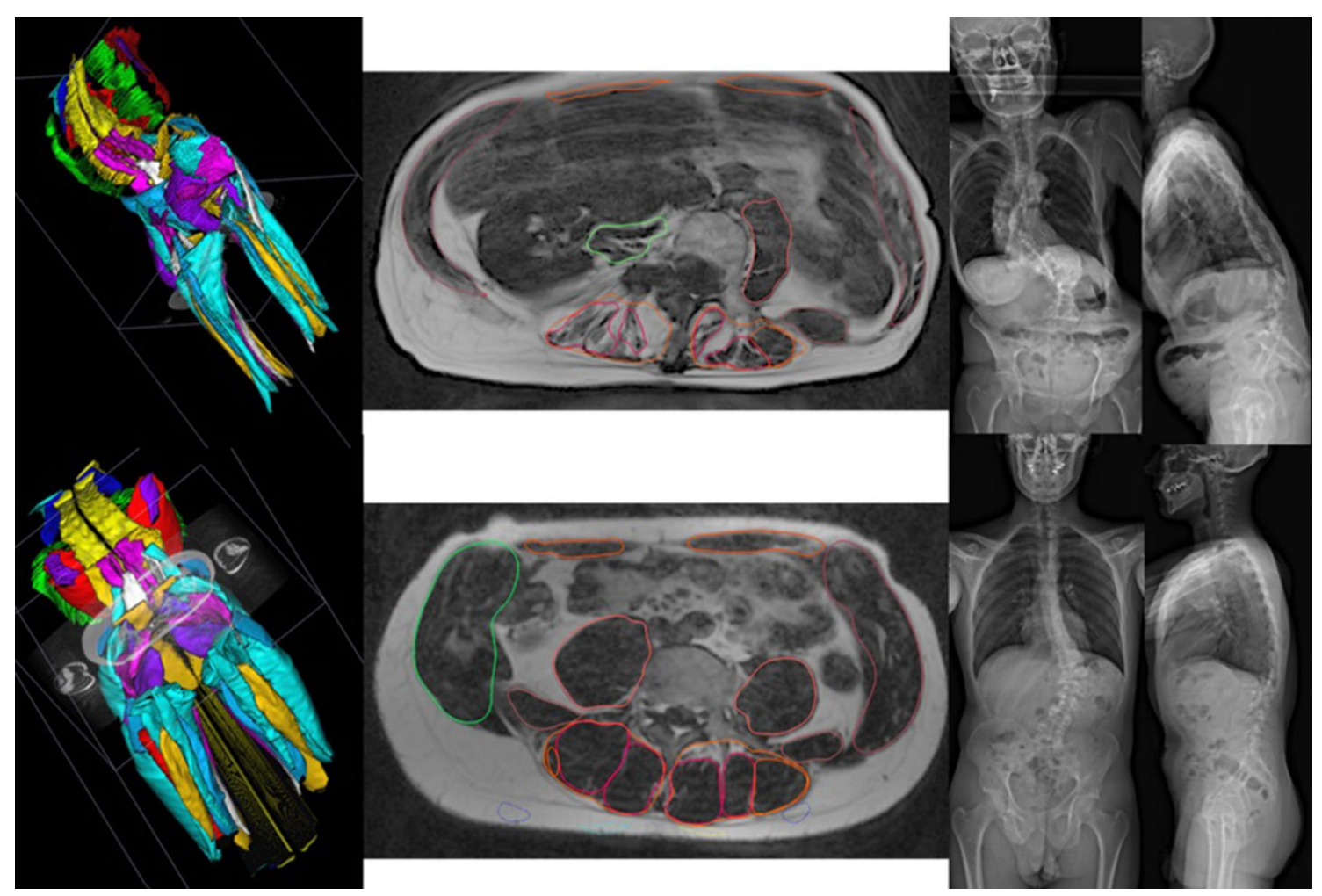

Fig. 4 3D muscular reconstructions of a 67 yo woman (top) and 40 yo man (bottom). There is smaller muscular volume and more fat infiltration in the oldest patients with the greater deformity 
patients with lumbar deformity can be explained by the need for a greater stabilizing action on the pelvis.

Future research could be interesting to explore preoperatively muscles of these ASD patients. This may allow better adaptation to the fusion, to potentially avoid the occurrence of mechanical complications such as junctional kyphosis. Hyun et al. in a series of 44 operated adult scoliosis patients found that more than $60 \%$ of fat infiltration of the spinal erectors was a risk factor for postoperative junctional kyphosis [22].

This study has certain limitations, including the small sizes of the cohorts, which may explain the absence of a significant difference in certain results (younger asymptomatic patients than old ones). Nevertheless, our findings are important with this being the first comparative study with 3D muscular volume analysis of ASD patients and subjects without deformity. In addition, muscles analyzed in the young subjects group were not exactly the same as those of the elderly, thus their analyses were separated. We have not investigated muscle volumes in patients with sagittal malalignment without coronal deformity, since all the patients had lumbar scoliosis. However, other studies have observed a decrease in volume and an increase in fat infiltration of spinal erectors in patients with loss of lumbar lordosis [13]. In a previous paper, we explained the consequences of coronal and sagittal malalignment on muscular volume and fat infiltration in ASD patients. We observed a tendency towards a loss of volume and an increase in fat infiltration in relation to the coronal and axial parameters. Sagittal malalignment, particularly anterior tilt and loss of lumbar lordosis, was associated with increased fat infiltration for all muscle groups (more severely for erector spinae, hip flexor and extensor), and decreased muscle volumes were associated with worst outcomes [12]. Finally, this study does not identify if differences in muscle volumes were a cause or a consequence of ASD. A longitudinal study on ASD patients would be interesting to investigate this potential causality in greater detail.

\section{Conclusion}

Our study demonstrates that muscular degeneration has a dual origin: aging and deformity. In particular, the volume of the spinal erectors is reduced in patients with deformity compared to healthy subjects. It is important to consider this muscular degeneration in the therapeutic strategy of ASD patients to adapt their treatment and prevent certain complications.

Authors contribution EF: Conception, data acquisition, formal analysis, and writing (draft-editing). WS: Conception, software, and revision. MK: Data acquisition, methodology, and revision. $\mathrm{RC}, \mathrm{AF}, \mathrm{AF}$ :
Data acquisition and revision. PG: Conception, supervision, and revision. VL: Conception, software, and revision. All the authors approved the version to be published; and agree to be accountable for all aspects of the work in ensuring that questions related to the accuracy or integrity of any part of the work are appropriately investigated and resolved.

Funding No funding was received for this work.

\section{Declarations}

Conflict of interest EF, MK, RC, AF, AF, and PG none. WS with Euros. VL with Globus, Nuvasive, Implanet, and Depuy Synthes.

Ethical approval Approved by local ethic committee.

\section{References}

1. Kebaish KM, Neubauer PR, Voros GD, Khoshnevisan MA, Skolasky RL (2011) Scoliosis in adults aged forty years and older: prevalence and relationship to age, race, and gender. Spine 36(9):731-736

2. Yadla S, Maltenfort MG, Ratliff JK, Harrop JS (2010) Adult scoliosis surgery outcomes: a systematic review. Neurosurg Focus 28(3):E3

3. Deyo RA, Mirza SK, Martin BI, Kreuter W, Goodman DC et al (2010) Trends, major medical complications, and charges associated with surgery for lumbar spinal stenosis in older adults. JAMA 303(13):1259-1265

4. Benoist M (2003) Natural history of the aging spine. Eur Spine J Off Publ Eur Spine Soc Eur Spinal Deform Soc Eur Sect Cerv Spine Res Soc 12(Suppl 2):S86-89

5. Trammell TR, Schroeder RD, Reed DB (1988) Rotatory olisthesis in idiopathic scoliosis. Spine 13(12):1378-1382

6. Schwab F, Farcy J-P, Bridwell K, Berven S, Glassman S et al (2006) A clinical impact classification of scoliosis in the adult. Spine 31(18):2109-2114

7. Lafage V, Schwab F, Patel A, Hawkinson N, Farcy J-P (2009) Pelvic tilt and truncal inclination: two key radiographic parameters in the setting of adults with spinal deformity. Spine 34(17):E599-606

8. Ferrero E, Liabaud B, Challier V, Lafage R, Diebo BG et al (2016) Role of pelvic translation and lower-extremity compensation to maintain gravity line position in spinal deformity. J Neurosurg Spine 24(3):436-446

9. Diebo BG, Ferrero E, Lafage R, Challier V, Liabaud B et al (2015) Recruitment of compensatory mechanisms in sagittal spinal malalignment is age and regional deformity dependent: a fullstanding axis analysis of key radiographical parameters. Spine 40(9):642-649

10. Diebo BG, Varghese JJ, Lafage R, Schwab FJ, Lafage V (2015) Sagittal alignment of the spine: what do you need to know? Clin Neurol Neurosurg 139(295):301

11. Meakin JR, Fulford J, Seymour R, Welsman JR, Knapp KM (2013) The relationship between sagittal curvature and extensor muscle volume in the lumbar spine. J Anat 222(6):608-614

12. Ferrero E, Skalli W, Lafage V, Maillot C, Carlier R et al (2019) Relationships between radiographic parameters and spinopelvic muscles in adult spinal deformity patients. Eur Spine J Off Publ Eur Spine Soc Eur Spinal Deform Soc Eur Sect Cerv Spine Res Soc. https://doi.org/10.1007/s00586-019-06243-3

13. Kang CH, Shin MJ, Kim SM, Lee SH, Lee C-S (2007) MRI of paraspinal muscles in lumbar degenerative kyphosis patients 
and control patients with chronic low back pain. Clin Radiol 62(5):479-486

14. Teichtahl AJ, Urquhart DM, Wang Y, Wluka AE, Wijethilake $P$ et al (2015) Fat infiltration of paraspinal muscles is associated with low back pain, disability, and structural abnormalities in community-based adults. Spine J Off J North Am Spine Soc 15(7):1593-1601

15. Amabile C, Moal B, Chtara OA, Pillet H, Raya JG et al (2017) Estimation of spinopelvic muscles' volumes in young asymptomatic subjects: a quantitative analysis. Surg Radiol Anat SRA 39(4):393-403

16. Zhang C, Moal B, Dubois G, Raya J, Lafage V, Skalli W (2014) Comparison of two MRI sequences for subject-specific 3D thigh muscle reconstruction. Comput Methods Biomech Biomed Engin 17(Suppl 1):136-137

17. Moal B, Bronsard N, Raya JG, Vital J-M, Schwab F et al (2015) Volume and fat infiltration of spino-pelvic musculature in adults with spinal deformity. World J Orthop 6(9):727-737
18. Moal B, Schwab F, Ames CP, Smith JS, Ryan D et al (2014) Radiographic outcomes of adult spinal deformity correction: a critical analysis of variability and failures across deformity patterns. Spine Deform 2(3):219-225

19. Dixon WT (1984) Simple proton spectroscopic imaging. Radiology 153(1):189-194

20. Ragan DK, Bankson JA (2010) Two-point dixon technique provides robust fat suppression for multi-mouse imaging. J Magn Reson Imaging JMRI 31(2):510-514

21. Hausselle J, Assi A, El Helou A, Jolivet E, Pillet H et al (2014) Subject-specific musculoskeletal model of the lower limb in a lying and standing position. Comput Methods Biomech Biomed Engin 17(5):480-487

22. Hyun S-J, Kim YJ, Rhim S-C (2016) Patients with proximal junctional kyphosis after stopping at thoracolumbar junction have lower muscularity, fatty degeneration at the thoracolumbar area. Spine J Off J North Am Spine Soc 16(9):1095-1101 